\title{
HOW TO DO THINGS WITH WORDS - HAIKAIS, DRONES E PORNOGRAFIA
}

\author{
Mariana Ruggieri ${ }^{*}$ \\ ${ }^{1}$ Universidade Estadual de Campinas, Campinas, São Paulo, Brasil
}

\section{Resumo}

O ensaio a seguir busca delinear algumas tensões referentes à ética e responsabilidade da e na literatura por meio da leitura e reflexão em torno de uma série de produções culturais recentes, entre elas o livro Point Omega, de Don Delillo, o curta-metragem "5,000 feet is the best", de Omer Fast, e a pornografia mainstream. Para tanto, adentraremos, por vezes, desde perspectivas pouco convencionais, questões de autoria e atos de fala, contando para isso com o auxílio teórico do livro Teoria do Drone, escrito pelo filósofo Grégoire Chamayou.

Palavras-chave: Don Dellilo; Ética; Drones; Pornografia.

\section{HOW TO DO THINGS WITH WORDS - HAIKUS, DRONES AND PORNOGRAPHY}

\begin{abstract}
The following article seeks to outline some of the tensions concerning the ethics and responsibility of and in literature through considerations surrounding several recent cultural productions, such as Point Omega, by Don Delillo, the short film " 5,000 feet is the best", by Omer Fast, and mainstream pornography. Questions of authorship and speech acts will be investigated with the theoretical aid of the book $A$ Theory of the Drone, written by philosopher Grégoire Chamayou.

Key-words: Don Dellilo; Ethics; Drones; Pornography.
\end{abstract}

*É doutora em Teoria Literária e Literatura Comparada pela Universidade de São Paulo. Foi pesquisadora visitante na Universidad Nacional Autónoma de México (2016) e na University of Michigan (2012). Mestra em Teoria Literária e Literatura Comparada pela Universidade de São Paulo. Bacharel em Estudos Literários pela Universidade Estadual de Campinas. Seu e-mail é ruggieri.mari@gmail.com. ORCID: 0000-0001-7867-6404. 
Em Point Omega, de Don Delillo, livro em que a violência parece nunca de fato irromper - embora seja possível intuí-la o tempo todo -, formas distintas de anonimato se delineiam pela impossibilidade de nomear a violência como tal e, consequentemente, pela impossibilidade de encontrar culpados. As partes "Anonymity 1" e "Anonymity 2" abrem e fecham o livro, respectivamente, em uma cena de exibição de uma vídeo-instalação de Douglas Gordon no Moma, 24 Hour Psycho, em que as $1 \mathrm{~h} 49 \mathrm{~m}$ do filme Psycho, de Alfred Hithcock, são expandidas para o período de vinte e quatro horas, a dois frames por segundo. Durante a cena famosa do assassinato de Marion Crane, pela lentidão da ação, os aros da cortina transformam-se em personagem principal da ação fílmica, desfazendo o suspense e o terror, e perdendo-se de vista o ponto de origem da ação, "like watching the universe die over a period of about seven billion years" (DELILLO, 2010, n.p), o que talvez até invalide a pergunta: quem é o assassino? ao mesmo tempo em que coloca outra: quem é responsável pelo fim do universo? Não que a revelação final em Psycho fizesse muita diferença; que ela também por si só já não invalidasse a pergunta, pois o que se irá afirmar, segundo o parecer final do psiquiatra Dr. Fred Richmond, é que Norman Bates, o assassino, é e não é Norman Bates. O que é mais notável, de todo modo, é que ninguém lembra o nome de Marion Crane. O narrador desta parte diz: "everybody remembers the killer's name, Norman Bates, but nobody remembers the victim's name. Anthony Perkins is Norman Bates, Janet Leigh is Janet Leigh. The victim is required to share the name of the actress who plays her" (DELILLO, 2010, n.p), uma observação que aponta para as dinâmicas de poder em que a vítima não pode ser nada além disso e o opressor pode habitar elusivamente o universo dos significados. Derrida, em "Racism's Last Word", descrevendo um movimento contrário a este, sugere que a palavra "apartheid" não teria sido traduzida para nenhuma outra língua, pois nenhuma outra língua teria querido hospedá-la, condenando-a a ser idêntica a si.

A ação propriamente dita da novela de Delillo transcorre entre as duas cenas no museu, estando assim emoldurada pela dilatação temporal da obra de Gordon e pela descrição precisa realizada pelo autor - sua ekphrasis levada à cabo com maestria -, que dita, por assim dizer, o ritmo da narrativa, além de transmitir ao leitor a radicalização da experiência voyeurística do cinema, de modo a armar, ainda que tangencialmente, os problemas que surgirão na parte da história que transcorre no deserto. O narrador, Jim Finley - um jovem diretor de cinema vai ao deserto na Califórnia para visitar Richard Elster, ex-consultor militar do governo de George Bush no que diz respeito à guerra no Iraque. Finley viaja de Nova Iorque para a casa de Elster no deserto na esperança de convencê-lo a tomar parte no seu projeto de filme. A intenção do jovem é realizar um documentário sobre Elster em tomada única, câmera fixa, emoldurando apenas a sua cabeça contra uma parede ao fundo. Elster fala da guerra, mas fala principalmente do vazio do deserto, do qual gostaria de fazer parte, uma espécie de desaparição que busca em nome de uma transcendência maior. A concepção para o documentário se opõe à instalação das partes que abrem e fecham o livro na medida em que a única ação propriamente dita será a das expressões faciais do seu objeto e a 
vocalização da guerra transcorrida em outro deserto, muito distante daquele em que se encontram.

Elster, aposentado de sua condição peculiar na capacidade de intelectual que auxiliou a inteligência do exército americano na guerra do Iraque, trabalhando no Pentágono com "the metaphysicians in the intelligence agencies and the fantasists in the Pentagon" (DELILLO, 2010, n.p), busca um descanso no deserto para "reclaim his body" (DELILLO, 2010, n.p). Ao longo dos dias, discorre sobre sua função na guerra e seus desejos. Elster passa os dias no deserto lendo Pound e Rilke. A descrição de sua função é vaga:

we tried to create new realities overnight, careful sets of words that resemble advertising slogans in memorability and repeatability. These were words that would yield pictures eventually and then become three-dimensional. (DELILLO, 2010, n.p)

Mais peculiares ainda são as circunstâncias da contratação de Elster, convidado ao seu posto de trabalho após a publicação de um ensaio acadêmico intitulado "Renditions". O título é significativo porque durante a guerra no Iraque as "extraordinary renditions", em que suspeitos eram levados a territórios onde as leis de interrogação eram mais relaxadas ou inexistentes para que tortura fosse realizada, foram empregadas à exaustão em nome da guerra ao terror ${ }^{1}$. Mas não é esse o assunto de Elster em seu texto, e ele é acusado de não fazer menção ao ato criminoso e à culpabilidade; no lugar disso há um estudo da palavra "rendition", com referências às suas diversas etimologias e usos.

Word origins and covert prisons. Old French, Obsolete French and torture by proxy. The essay concentrated on the word itself, earliest known use, changes in form and meaning, zero-grade forms, reduplicated forms, suffixed forms. There were footnotes like nested snakes. But no specific mention of black sites, third-party states or international treaties and conventions. (DELILLO, 2010, n.p)

O diretor de cinema se pergunta sobre o que Elster pensava da acusação de que havia tentado encontrar mistério e romance em uma palavra que estava sendo usada como um instrumento de segurança nacional, "a word redesigned to be synthetic, concealing the shameful subject it embraced?" (DELILLO, 2010, n.p). Talvez por isso seja curioso quando, refletindo sobre a guerra falida no Iraque, e desejando uma outra versão da mesma guerra, Elster diz: "I wanted a haiku war. I wanted a war in three lines. Haiku means nothing beyond what it is. This is the soul of haiku. Bare everything to plain sight" (DELILLO, 2010, n.p), ou seja, uma guerra que significasse apenas exatamente o que significava. Elster não é contra a guerra, mas afirma desejar uma guerra melhor, em que as coisas são o que são, "but in those rooms, with those men, it was all priorities, statistics, evaluations, rationalizations" (DELILLO, 2010, n.p). Ali no deserto, no entanto, Elster está envolvido em outra guerra, uma guerra contra o tempo, assim como o narrador 
de "Anonymity 1"; "to feel time passing, to be alive to what is happening in the smallest registers of motion" (DELILLO, 2010, n.p), aguardando a chegada do ponto ômega, o ponto final de convergência final do universo, "the dream of extinction" (DELILLO, 2010, n.p). Uma bomba nunca é o suficiente, ele argumenta, e o ponto ômega, portanto, passa a ser a realização do seu desejo genocida. "Back now to inorganic matter. This is what we want. We want to be stones in a field" (DELILLO, 2010, n.p). Não podemos nos esquecer que na Bíblia, mais especificamente no Livro do Apocalipse, é possível ler que: "Eu sou o Alfa e o Ômega, diz o Senhor Deus".

\section{///}

Se é possível escanear o ultra-espaço e o intra-espaço, é porque a tecnologia privilegia a extensão da visão ao longo dos vastos territórios sobre os quais o ser humano tem fincado as suas bandeiras. A expressão "a se perder de vista" não teria mais a mesma eficácia; o seu equivalente em inglês, "as far as the eye ${ }^{2}$ can see", passa a se referir a quase tudo. O olho chegou em toda parte, dotado da capacidade de ajustar a escala, o contraste e a cor daquilo que se quer tornar visível. Donna Haraway, em "Situated Knowledges: The Science Question in Femininism and the Privilege of Partial Perspective", afirma que:

Vision in this technological feast becomes unregulated gluttony; all perspective gives way to infinitely mobile vision, which no longer seems just mythically about the god-trick of seeing everything from nowhere, but to have put the myth into ordinary practice. And like the god-trick, this eye fucks the world to make techno-monsters. ${ }^{3}$ (HARAWAY, 1991, p.189)

E se o ser humano pudesse não só triar, mas matar com o olho - um olho que nunca pisca? ${ }^{4}$ Em outras palavras: e se esse olho tivesse um dedo no gatilho? Um dispositivo, uma câmera letal que tem o poder de realizar uma ação sobre aquilo que se filma. $\mathrm{O}$ anjo da história é um anjo caído. Reerguido por um drone, ele agora percorre os céus novamente. A esse drone chamamos de progresso.

A pergunta o que a literatura tem a ver com um drone? - que pode também vir em forma de acusação: o que pode a literatura ter a ver com um drone? - é, evidentemente, bastante plausível. W. G. Sebald tem uma série de palestras, intituladas "Air War and Literature", que poderiam servir como pista, mas ali está bastante claro que a literatura, ou pelo menos a literatura alemã após a segunda guerra mundial, quis de todas as formas desassociar-se dos bombardeios aéreos. Uma foto tirada em Israel em 2006 pode, talvez, elucidar a questão e restaurar algum tipo de esperança para o rumo deste texto. A cena é atroz e não por isso menos complexa: crianças israelenses escrevem mensagens com canetinhas coloridas em mísseis destinados ao território libanês - "To Nasrallah, with love". Apesar do horror, tudo, é claro, parece apontar para a inocência dessas crianças. Além do fato inassimilável de serem crianças, é necessário também constatar que não serão elas a enviar a mensagem, a detonar o explosivo. Também não será 
Sayyid Hassan Nasrallah a receber a mensagem que, certamente, ficará pelo caminho - e nesse caminho, não podemos nos enganar, há gente. A cena toda vai se construindo de modo a separar cada vez mais a inscrição da mensagem das ações - isto é, da destruição - que a seguem, e a espiral das leituras possíveis se desenha para fora, rodeando a cena da escrita em círculos, cada vez mais longe, uma lista de poréns - os pais, o circo midiático, as crianças-soldados do Hezbollah, a guerra. No que constituiria esse modo de enunciação particular? De alguma forma, não seriam os mísseis lançados, pelo menos dentro de certo regime discursivo, em nome de sua defesa, da defesa daquelas crianças - em nome daqueles que não podem responder pelo que dizem? Não é sempre isso que está em jogo quando adentramos o lugar perverso constituído pelo "em nome de"? O slogan Not in my name, bastante comum nas manifestações contra a guerra no Iraque, parece apontar para algo nessa direção. E quanto àqueles que não estão em condições nem de afirmar-negar: não em meu nome?

Mas dissemos que falaríamos aqui sobre drones, e o drone é um olho armado com um dedo no gatilho acoplado a um corpo sentado a milhares de quilômetros de distância em uma sala com ar-condicionado nos arredores de Las Vegas, onde além de luzes há artistas cover, entre os quais soldados que matam sem ir para a guerra. O absurdo da situação torna possível uma formulação alternativa à pergunta acima: em que pode um drone se parecer com a literatura? A pergunta também pode parecer absurda, inclusive pelo desconforto que gera, ao sugerir que haveria algo de literário em um drone, porque conceder estatuto especulativo - a chance de se apresentar como aquilo que não é - a uma máquina de guerra, embora possível, talvez seja pouco estratégico, ${ }^{5}$ mas acontece que nem toda literatura é ficção, nem toda ficção é não-real, e assim por diante.

No curta-metragem "5,000 Feet Is the Best", de Omer Fast, de 2011, um ex -operador de drones no Afeganistão e no Paquistão descreve porque cinco mil pés é a melhor altura para voar. Sua voz é sobreposta à imagem (filmada por um drone) de um menino andando de bicicleta no que, a julgar pelo deserto, parece ser um subúrbio de Las Vegas. O descampado árido do início da filmagem, por um momento, indica a possibilidade desse menino ser um menino qualquer afegão, mas logo a bicicleta chega a um bolsão residencial com cercadinhos brancos e piscinas, e as coincidências, evidentemente, acabam - o drone que filma esse menino branco de mochila não se chama Reaper ou Predator. A voz em off diz:

5000 thousand feet is the best. At 5000 thousand feet I can tell you what type of shoe you are wearing from a mile away. I can tell a person's clothes, beard, hair color. We have the IR infrared which you can switch to automatically and that'll pick up any heat signature or cold signatures. I mean if someone sits down let's say on a cold surface for a while then gets up you'll still see the heat from that person for a long time. It kind of looks like a cold blossom shining up in heaven. It's quite beautiful. I mean if someone lights up a cigarette, that's a huge beacon you see, you just see a very white glow coming from that area and you could be following them and they won't see you or hear you. (FAST, 2011) 
A intimidade que o operador de drone desenvolve com seus potenciais alvos é desconcertante, porque é invasiva e destrutiva e também porque o operador nunca poderá ver a vítima vendo-o matá-lo, os olhares nunca se cruzam. It's quite beautiful: seria o caso de discutir - de desautorizar - a beleza em questão? Arte e horror, na figura do sublime, parecem estar interligadas em mais de uma ocasião, como por exemplo quando Sebastião Salgado no filme "The Salt of the Earth" comenta o fato de que foi obrigado a ir embora do campo de petróleo Burgan, completamente em chamas: "foi uma dor no coração abandonar um espetáculo tão grandioso". Karlheinz Stockhausen, em leitura absolutamente desnorteante sobre $o$ ataque de 11 de setembro às torres gêmeas diz que:

the greatest work of art that is possible in the whole cosmos (...) you have people who are so concentrated on one performance, and then 5000 people are dispatched into eternity, in a single moment. I couldn't do that. In comparison with that, we're nothing as composers. (TOMMASIN, 2001)

Há, porém, algo mais: a guerra dirigida pelos UAVs (Unmanned Aerial Vehicles) coloca em prática a possibilidade de ver sem ser visto e, principalmente, de matar sem morrer - uma situação, em suma, de não-resposta absoluta. Se o drone não responde por si, não há como responder a ele. Mais do que qualquer situação de desigualdade em um conflito, o que a guerra por drones instaura como política é a neutralização de toda possibilidade de reação. Em outras palavras, não é tanto que a guerra por drones desarticula de modo preciso, eficiente e veloz qualquer chance de contraofensiva, mas a contraofensiva é reduzida desde o início à cena patética de atirar para o céu às cegas, sabendo que não há ninguém lá. O operador de drones segue na instalação de Fast:

Then we do something called the 'light of God' - the marines like to call it the 'light of God' - it's a laser-targeting marker. We just send out a beam of laser and when the troops put on their night-vision goggles, they'll just see this light that looks like it's coming from heaven, pfft, right on the spot. Coming out of nowhere from the sky. It's quite beautiful. (FAST, 2011)

É a possibilidade de estetizar a violência que aproxima o drone da literatura, um flâneur homicida dos céus? Em Estrella Distante, livro do chileno Roberto Bolaño, o personagem principal, Carlos Wieder, é um poeta que frequenta oficinas literárias, organiza eventos artísticos e também trabalha como torturador para o regime militar chileno. Escrevendo com um avião poemas no céu, parece relacionarse de alguma maneira ao sentimento descrito pelo operador de drones: "La muerte es mi corazón. Y después: Toma mi corazón. Cuando avistó el aeródromo escribió: La muerte es comunión"6 (BOLAÑO, 2001, p.90). O futurista italiano Fedele Azari lança do céu, em 11 de abril de 1919, o manifesto intitulado Il Teatro Aereo Futurista, uma defesa de um modo de conceder liberdade às palavras, escrevendo-as no céu de modo a constituir uma forma de expressão, segundo ele, verdadeira, absolutamente livre, viril e enérgica que conduziria à grande nação futurista. Ele diz: 
HO ESEGUITO IO STESSO, NEL 1918 [durante a guerra, portanto], MOLTI VOLI ESPRESSIVI E SAGGI DI TEATRO ELEMENTARE SUL CAMPO DI BUSTO ARSIZIO. Ho constatato como sia facil per gli spettatori seguire tutte le sfumature di stati d'animo dell'aviatore, data la identificazione assoluta tra il pilota e il suo apparecchio, che diventa come un prolungamento del corpo: le ossa, i tendini, i muscoli e i nervi si prolungano nei longheroni e nei fili metallici. ${ }^{7}$ (AZARI, 1919)

Richard Brautigan escreveu, em 1967, durante um breve período de residência poética na Caltech, o poema "All Watched Over by Machines of Loving Grace", cuja última estrofe aposta na comunhão entre homem e máquina, uma harmonia programada por uma força divina e cibernética: "I like to think / (it has to be!) / of a cybernetic ecology / where we are free of our labors / and joined back to nature, / returned to our mammal / brothers and sisters, / and all watched over / by machines of loving grace" (BRAUTIGAN, 1967).

Não é sem motivos, dirá Benjamin Noys em "Drone Metaphysics", que a imagem de Deus é retomada de novo e de novo no universo discursivo dos drones. Segundo o autor, os UAVs codificam certo discurso teológico e corporificam desejos de transcendência - um operador de drone teria dito certa vez: "sometimes I feel like a God hurling thunderbolts from afar". Claro, há instantaneidade, imediatez, onipotência e onividência. Noys diz que os drones carregam consigo não apenas munição, mas também uma promessa metafísica, uma convergência entre o militarismo e a metafísica: uma forma particular de um sujeito sem sujeito. Então, ainda que os drones não sejam completamente automatizados, isto é, ainda que existam seres humanos participando do que Noys chama de "the kill chain", possibilitando locais de intervenção política,

these humans are constituted in ways to make them resist calls on their humanity and they are called to conform to the drone. Adorno's prescient insight confirms that the achievement of 'subjectlessness' is not simply the effect of automation, but a labour by the subject that operates on itself in the process of self-automation, or the creation of an 'automatic self'. (NOYS, 2015, p.7)

Há o que ele chama de uma semelhança ao ódio que os gnósticos têm da matéria. Esse gnosticismo militar, ele diz, defende que a alma poderosa é desterritorializada, fluida e transferível, ao passo que a alma fraca está presa no corpo e no mundo.

This is to challenge certain discourses of 'acceleration' that regard resistance as lying in a capacity of excess, the friction-less, hypertrophy, and so forth that are claimed to outpace the forms of military, state, and capitalist power. The desire for a final deterritorialisation that can slip into a smooth space of resistance is not only unfaithful to Deleuze and Guattari's warning '[n]ever believe a smooth space will suffice to save us', but also remains within the field of drone metaphysics. (NOYS, 2015, p.16) 
A pergunta, então, finalmente pode se estabilizar na seguinte conformação: $o$ que acontece quando do outro lado não há um corpo? - uma pergunta que simultaneamente implica outra: o que acontece quando do outro lado há um corpo que não pode morrer? Uma forma de intervenção remota que, diferente da hipnose, prescinde de um corpo mediador. O drone como máquina produtora de um estado de exceção móvel que se instaura onde quer que seja, incondicionalmente, isto é, sem que nada o condicione, a partir do qual é possível erigir, por exemplo, muros invisíveis ou por meio do qual é possível implementar procedimentos extrajudiciais que tornam prisões como Guantánamo obsoletas. Pensando nas leituras de Derrida a respeito de Walter Benjamin, ${ }^{8}$ torna-se bastante difícil não ler a primeira tese em "Sobre o conceito da história" com algum pesar diante da aposta eufórica no autômato invencível que é, em verdade, um ciborgue com ares messiânicos a vencer as guerras feudais do tabuleiro de xadrez.

Em Teoria do drone, de Grégoire Chamayou, há uma discussão interessante a respeito das semelhanças e diferenças entre kamikazes e drones. ${ }^{9}$ Ambos são bombas com olhos; o primeiro tem como arma o corpo, o segundo é uma arma sem corpo. O drone, no entanto, é visto, geralmente, como uma arma moralmente superior, promovedora de uma morte mais higiênica, noção curiosa já que a única vida que ela preserva é de quem comete o ato de matar. Interessante cálculo este, em que é mais digno o algoz não morrer com a vítima do que partilhar do mesmo destino, um afastamento absoluto do sacrifício como discurso primeiro da guerra. Em ambos os casos, o horror dos métodos empregados parece estar situado na exclusão a priori de qualquer esboço de resposta: o suicida-homicida por perpetrar simultaneamente crime e punição; o tele-homicida por, apesar da dissolução da premissa do combate - a mesma chance de morrer que de matar -, ter sua atividade enquadrada dentro da normalidade da guerra. No caso do drone, o paradoxo é que, em rigor, com tal autonomização da decisão letal, o único agente humano diretamente identificável como sendo a causa eficiente da morte seria a própria vítima, que terá tido a infelicidade, pelos movimentos inapropriados de seu corpo, como já era o caso com as minas antipessoais, de detonar sozinha o mecanismo automático de sua própria eliminação.

Depois de passar por toda uma discussão sobre a teoria do estado e da soberania, explorar as fases distintas do contrato social, desde Hobbes, segundo o qual o soberano protege a população em tempos de paz, ao passo que em tempos de guerra é a população que protege o soberano, Chamayou chega à relação entre $\mathrm{o}$ welfare state e o warfare state. $\mathrm{O}$ estado de bem-estar social surge como consequência do grande contingente de soldados mobilizados em guerras, cuja lacuna social deveria ser apaziguada de alguma forma. Com o declínio da garantia de estabilidade socioeconômica, seria preciso buscar formas de fazer guerra que não passassem pelo alto dispêndio de vidas. Sugere-se, portanto, que a dronização é um fenômeno que serve como contraponto à precarização da vida em geral. No entanto, o efeito estrutural dessas mutações do modo de guerra é, em realidade, uma precarização mais profunda das formas de vida, pois ao reduzir-se "a dependência material do aparelho de Estado para com o trabalho militar, e por 
meio disso sua dependência social para com os corpos que constituíam essa força de trabalho" (CHAMAYOU, 2015, p.212), os corpos tornam-se prescindíveis, assim como os mecanismos que proporcionariam a esses mesmos corpos uma vida mais digna. A desestabilização do contrato social por meio da dronização desativa a possibilidade de postura crítica daqueles que estariam colocando seus corpos em risco, ou seja, desmonta qualquer possibilidade de protesto que tenha como local de enunciação o próprio corpo a ser colocado em combate (pensemos aqui, por exemplo, na guerra do Vietnam). Chamayou diz que

se as democracias liberais desenvolvem síndromes "de aversão pelas perdas", não é porque, como se acredita, elas atribuem um valor por demais elevado à vida de seus cidadãos, mas, ao contrário, porque já não dispõem senão de um conceito muito pobre do que é a vida, segundo a qual preservar a vida física prevaleceria a qualquer preço, mesmo em detrimento da natureza dos meios empregados, sobre a salvaguarda de uma vida ético-política superior a esta. (CHAMAYOU, 2015, p.198)

Se essa provocação leva à reflexão sobre a ausência de condições da vida que se diz proteger, por outro lado assemelha-se perigosamente ao discurso necropolítico, segundo o qual se mata em nome de um conceito muito pobre do que é a vida e sobre a salvaguarda de uma vida ético-política superior; pensemos, por exemplo, na advogada que foi demitida da rede de notícias CBS após escrever em rede sociais que não sentia nenhum tipo de simpatia pelas vítimas do tiroteio em Las Vegas pois, segundo ela, fãs de música country seriam todos republicanos portadores de armas.

Na cidade de Madrid, em abril de 2015, houve o primeiro protesto holografado de que se tem notícia, em que as pessoas poderiam, desde suas casas, retransmitir sua imagem a ser holografada na frente do parlamento espanhol, em resposta à lei de 2013 que impedia a congregação de pessoas diante de prédios governamentais sem autorização prévia. Mais do que propor uma nova era do protesto, em que a hiperconectividade, aliada às tecnologias de imagem, viriam a suplantar a presença corpórea dos protestos, estava posta em cena a situação inusitada em que as imagens das pessoas pareciam ter mais direitos de trânsito do que as pessoas em si, e o corpo era impedido de manter sua posição ativa no fazer político, algo como a transformação e redução da política a uma telepresença. Em Notes Toward a Performative Theory of Assembly, Judith Butler parte do pressuposto de que os significados políticos de corpos reunidos não podem se reduzir àqueles colocados em cena pelo discurso. Ainda que nem todo mundo possa aparecer em forma de corpo, ações corporificadas podem significar de maneiras que não são estritamente discursivas ou pré-discursivas, e é nesse sentido que a liberdade de reunião e a liberdade de expressão constituem-se como garantias distintas, o que quer dizer que uma pode existir sem a outra:

We might be tempted on the basis of older habits to say, "but if it (the body) signifies, it is surely discursive", and maybe that is true. But that 
rejoinder, even if it holds, does not let us examine that important chiasmic relation between forms of linguistic performativity and forms of bodily performativity. They overlap; they are not altogether distinct; they are not, however, identical with one another. (BUTLER, 2015, p. 9)

Chamayou, via Hannah Arendt, sugere que é o próprio fato do Estado necessitar do corpo de seus cidadãos, até mesmo os Estados mais autoritários, que o impede de ser pura violência - o poder como sujeição dos corpos. A dissolução desse pacto - que mais bem é uma chantagem - pela substituição da produção e da guerra por autômatos coloca os corpos em situação de vulnerabilidade, pois o poder pode reverter-se em pura violência, os drones utilizados contra a própria população; no entanto, por outro lado, reciprocamente, é também possível imaginar que sem a mobilização de corpos por parte do Estado, ficamos mais próximos da dissolução do poder: da mobilização dos corpos contra o Estado, reduzido a um aparelho. Mas talvez não seja possível ser tão otimista: onde está, hoje, o sujeito do poder?

Esse sujeito está precisamente em qualquer lugar em que ele se empenhe ativamente para se fazer esquecer. É inclusive essa intensa atividade de apagamento de si mesmo que o anuncia inevitavelmente. Toda uma agitação subjetiva, com esforços e investimentos enormes, para confundir as pistas, apagar os rastros, escamotear qualquer sujeito discernível da ação, com o fim de travestir essa ação em puro funcionamento, uma espécie de fenômeno natural, dotado de um tipo de necessidade similar, só que dirigido por administradores de sistemas que vez por outra corrigem seus bugs, efetuam atualizações e regulam os acessos. (CHAMAYOU, 2015, p. 228-229)

Se a política passa necessariamente pelo corpo, pelos corpos em corpo a corpo, talvez a possibilidade de comparecer à cena da disputa seja insuperável para qualquer ação que se pretenda ética, em que o poder sobre os corpos passa para uma política dos corpos, com os corpos, pelos corpos, para os corpos. Se os drones agem, segundo a propaganda oficial, preventivamente, monitorando alvos e ligações de celular, compondo um arquivo extenso por meio do qual se constroem genealogias do mal, eliminando os tentáculos para tentar chegar até a raiz, não é nem possível mais dizer que há um crime subjacente ao inimigo; ou seja, de acordo com a nomenclatura schmittiana de guerra, não há amigo ou inimigo, não há guerra, só há mesmo assassinato, corpos vigiados, arbitrariamente julgados e sentenciados com o auxílio de algoritmos que processam dados, encurralados em um visor de alta precisão para, finalmente, serem derrubados, corpos cujos enterros são então assistidos em Las Vegas para a obtenção de mais dados, que voltam a alimentar as bases de dados. Uma chacina articulada eminentemente por códigos, e que se vale de suas elaboradas equações para reivindicar-se humanitária, o que no fundo só revela o delírio subjacente àquilo que se afirma como uma necroética empregada em prol do bem da humanidade em geral, data crunchers não-humanos mais humanos que os humanos. Como disse certa vez Eduardo Viveiros de Castro: ou o pós-humanismo é menos que o humano, ou 
ele não é ${ }^{10}$. Ao contrário do que sugerem os roteiros de ficção científica, o perigo não é que os robôs comecem a desobedecer; é precisamente o inverso: que nunca desobedeçam, que não haja possibilidade de insubmissão.

\section{//I}

Arremessado de 5000 pés de altura, um livro pode certamente matar (um livro pesado, que vencesse com facilidade a resistência do ar), mas, para além disso, talvez ainda seja possível argumentar que o paralelo entre a literatura e o drone é descabido. Ainda assim, também não seria impossível argumentar que a literatura mata, à sua forma, ou se alia a métodos de morte: a leitura que sugerimos é transversal, não tanto uma analogia, mas uma investigação sobre a ausência de um corpo que possa responder pela violência perpetrada - a invencibilidade garantida pela imunidade. Derrida, em Passions, e também em This Strange Institution Called Literature, diz da literatura como aquilo que tem o direito absoluto à não-resposta, isto é, podendo dizer tudo, não precisaria responder a nada; não precisa responder por nada - uma conformação ética peculiar, que, se por um lado, resiste ao perigo sempre iminente da censura, por outro torna-se porto seguro para qualquer tipo de pensamento e expressão, absolutamente imune a qualquer pergunta, pensamentos e expressões, inclusive, dos quais nos tornamos, de certa forma, cúmplices enquanto leitores que assumem o eu da narrativa. ${ }^{11}$

André Breton, em uma nota de rodapé no seu "Manifesto do Surrealismo", propôs que a literatura seria resultado da hipnose e que, portanto, em um tribunal, autor e o juiz teriam a mesma responsabilidade - isto é, nenhuma - pelo texto. Nesse tribunal hipotético, diz Breton:

Limita-se em sua defesa a afirmar que não se considera autor de seu livro, não podendo este passar senão por uma produção surrealista, que exclui toda questão de mérito, ou de demérito de quem o assina, que ele se limitou a copiar um documento sem dar sua opinião, e que ele é pelo menos tão estranho quanto o presidente do Tribunal ao texto incriminado. (BRETON, 2001, p. 44)

Para Foucault é o próprio tribunal que dá origem à noção de autoria, primeiro contra a heresia, no final da Idade Média, depois em favor da propriedade privada dos direitos autorais, com o advento da imprensa. A dissolução do autor como origem é a dissolução ou a inoperância do tribunal e é por isso que Breton, de modo nostálgico, lamenta que já não haja tantos processos nos quais poderia colocar em marcha essa inoperância por meio da escrita surrealista. É como se legitimar o surrealismo dependesse de deslegitimar a autoridade do autor. Por outro lado, também, talvez fosse possível dizer que o lamento de Breton tivesse a ver com o reconhecimento de certa neutralização da literatura, processo que já não a tornava digna de um tribunal e diante do qual o autor, portanto, já não tinha a mesma importância - uma desimportância distinta daquela buscada por Breton. Em 1968, Barthes decreta a morte do autor: "a escritura é esse neutro, 
esse composto, esse oblíquo pelo qual foge o nosso sujeito, o branco-e-preto em que vem se perder toda identidade, a começar pela do corpo que escreve" (BARTHES, 2004, p. 57). É a saída de cena do corpo do autor, uma dessubjetivação mediada pela escrita, um reconhecimento da contingência da escrita, da contingência daquilo a que nomeamos sujeito. Embora ambos coincidam no fato de que o autor não existe como origem da literatura, os argumentos de Breton são distintos aos de Barthes na medida em que para Breton o corpo do autor é mero mediador de forças ocultas enquanto que para Barthes já não há corpo. ${ }^{12} \mathrm{Na}$ concepção foucaultiana, o nome do autor também não está atrelado propriamente a um indivíduo real e exterior que proferiu um discurso, mas remete a um certo tipo de discurso com estatuto específico. Quando Breton fala em uma gradação de responsabilidade, das acusações feitas pelos tribunais, o interesse dele não parece ser, a princípio, refutar as acusações nos termos mesmos da acusação, mas simplesmente inviabilizá-las por meio da supressão de um ator consciente de seus atos. O que Barthes propõe, no entanto, é também uma sobrevida ao tribunal, ou uma proposição que deixa espaço para outro tipo de tribunal, ao transferir o poder aos leitores e a cadeira de réu para o sentido. Se a linguagem não pertence a ninguém, isto é, se o seu local não está previamente designado, ela é infinitamente apropriável, o que equivale a dizer que ela está sempre sob disputa - sua significação sempre à beira da totalização - e que essa disputa não é interna à linguagem, embora seja imanente à sua condição. Mantê-la deslocada de seu próprio lugar, ou seja, sem que ela se torne vulnerável a si própria, portanto, seria mantê-la em disputa ou, ao menos, defendê-la como disputável, reconhecendo simultaneamente sua fixidez e o seu ponto de fuga. Esse movimento, porém, faz com que a imunidade passe do autor ao sentido - um sentido pelo qual nunca é possível responder, pois não há prova final. Como ter certeza de que tal movimento também não se torna um método universal em que a literatura engendraria a diferença a priori, em uma espécie de Deus É Amor, onde ela também seria a sua própria garantia e, portanto, diante da qual seria impossível se posicionar, sobre a qual seria impossível decidir? E o que dizer do risco, se o risco é sempre do outro?

\section{///}

Enquanto transcorrem as conversas sobre a guerra, a filha de Elster, Jessie, também chega à casa no deserto, com o intuito de esconder-se de um relacionamento abusivo com um homem em Nova Iorque. Mas ali ela também tem dificuldades em encontrar um espaço seguro, tendo seu espaço invadido por Finley, que, obcecado, aparece na porta do seu quarto uma noite, abre-a um pouco mais e a olha ali, apesar de não ter tido qualquer tipo de sinal afirmativo em nenhuma de suas tentativas prévias, para perceber então que ela o vê olhando para ela. Em outros momentos, Finley a observava de longe, "I found it disturbing to watch her, knowing that she didn't feel watched” (DELILLO, 2010, n.p). Neste dia em que ela o vê, Jessie vira para o outro lado e se cobre com o lençol até o pescoço. No dia seguinte ela desaparece. Não fica claro se é assassinada, se pelo homem 
de Nova Iorque, cujo nome não sabemos ao certo, mas que muito possivelmente se chama Dennis, ou se desaparece voluntariamente do mundo, como seu pai, que se pergunta: "Do we have to be human forever?" (DELILLO, 2010, n.p), com a diferença de que seu pai parece querer desaparecer por sentir sua consciência pesar pelos rumos da guerra, ao passo que Jessie parece não conseguir responsabilizar ninguém pelas violências sofridas. Sabemos muito pouco de Jessie, sua voz aparece raramente, quase tudo que sabemos dela é mediado por Finley or Elster. Sua mãe, quem talvez saberia dizer alguma coisa relevante, é reduzida a uma voz no telefone. É justamente por ela que sabemos que Jessie recebia ligações constantes de um número anônimo "BLOCKED CALLER", motivo pelo qual a mãe considera importante para a filha passar alguns dias no deserto com o pai. Mas ali ninguém fala sobre isso; ao contrário, Elster desmerece as preocupações da mãe de Jessie, sua ex-eposa. Finley quer ficar com Jessie. Elster a vê como uma extensão de si. Não sabemos nada sobre o que ela quer, do que tem medo, se tem medo, se tem desejos. Enquanto Jessie dorme, eles conversam sobre o exagero das mulheres e dizem que são todas loucas. Quando Finley diz que é sua ex-mulher quem o considera louco, Elster responde: "I don't know. What are you protecting? She's crazy. Say it" (DELILLO, 2010, n.p).

O comando de Elster é claro: diga. Ao dizer que ela é louca, a loucura dela se torna um fato, uma admissão, uma confissão. Essa é a natureza do papel que Elster ocupou na guerra, a de quem criava realidades com palavras. Em "How to Do Things with Pornography", Nancy Bauer retoma as palestras de J.L. Austin, How to Do Things with Words, para compreender exatamente o que a pornografia faz, no sentido forte da palavra "fazer", naquilo que Austin chama de ato ilocucionário. $\mathrm{O}$ interesse de Bauer não é, portanto, apenas no efeito que a pornografia gera, naquilo que é perlocucionário, mas naquilo que seria inerente à pornografia. A sua hipótese é de que a pornografia, ou certa pornografia, como forma de expressão, mais do que dar ideias e construir uma gramática sexual em que a mulher é discriminada como objeto, transforma um "não" em um "sim". Essa diferenciação para ela é importante porque a defesa da liberdade de expressão afirma que não é possível proibir algo que não seja discriminatório em si mesmo, ou seja, algo que apenas gere discriminação por meio da intermediação e ação de outras pessoas: "pornography, no matter how systematic its discriminatory effects, cannot be said to discriminate against women in and of itself and therefore must count, legally at least, as a protected form of expression" (BAUER, 2015, p.77). A questão é de ordem discursiva, não levando em conta as condições de produção dos filmes pornográficos, o que seria uma outra questão, ainda que bastante importante. A defesa da pornografia pelas leis de liberdade de expressão é importante para protegê-la contra acusações de obscenidade e da interdição a fantasias não-normativas. Bauer, no entanto, busca responder o que a pornografia de fato consegue fazer, em si mesma, e sugere que, além de legitimar a violência contra a mulher, portanto, certa pornografia priva as mulheres das condições contextuais que devem operar para que suas vozes sejam ouvidas. Há o que ela chama de "incapacitação ilocucionária"; isto é, as mulheres, apesar 
de - em situações ideais - poderem enunciar as palavras que querem enunciar, veem-se removidas de sua capacidade de conseguir o que querem conseguir com a enunciação. Se, portanto, os homens estão condicionados por certa pornografia a não reconhecer as palavras das mulheres como uma recusa, ela não será capaz de recusar. Certa pornografia silencia as mulheres não em suas locuções, mas em suas ilocuções, e condena-as a performar atos ilocucionários em um vazio em que o "não" nunca é apenas um "não" porque esse "não" é também um "sim", uma perversão do sentido.

Na parte que fecha o livro "Anonymity 2", tudo leva a crer que a personagem diante da obra de Douglas Gordon é Jessie. "Anonymity 2" se passa exatamente um dia antes de "Anonymity 1", ambos episódios cronologicamente anteriores às semanas passadas no deserto. Ambas as partes são narradas pelo mesmo homem, que vai todos os dias à exposição assistir à exibição lenta de Psycho. Talvez seja ele o responsável pelas chamadas anônimas, o rapaz que possivelmente se chama Dennis. Ele pede o telefone dela, e ela parte. Ele retorna à exposição. Tanto este narrador, quanto Finley na parte em que é narrador, têm dificuldade em realizar leituras a respeito da reciprocidade do desejo de Jessie e, consequentemente o leitor, e inclusive a leitora, encontram também dificuldade para medir o seu desconforto, para sensibilizar-se às suas reações menos perceptíveis aos avanços de ambos os homens, respostas que não são nunca nem um não nem um sim, ou melhor, leituras masculinas de respostas que não são nunca nem um não nem um sim e, portanto, com quase toda a certeza, devem ser um sim. Não é, portanto, que a instabilidade se converta em um álibi perfeito, mas que a sua promoção a qualquer custo se torna o próprio local do crime.

\section{Notas}

1. Ver o relatório de 213 páginas publicado pelo Open Society Foundations, disponível em https://www.opensocietyfoundations.org/reports/globalizingtorture-cia-secret-detention-and-extraordinary-rendition, noticiado pelo jornal britânico The Guardian em 5 de fevereiro de 2013, disponível em: https://www. theguardian.com/world/2013/feb/05/cia-rendition-countries-covert-support. Ver também o artigo de Leila N. Sadat: "Extraordinary Rendition, Torture and Other Nightmares from the War on Terror". In: George Washington Law Review, Vol. 75, p. 101, 2007.

2. É interessante também pensar que em inglês há homofonia entre "eye" e "I", o eu como a medida de todas as coisas.

3. Um dos sistemas de segurança desenvolvidos pelo Departamento de Defesa norte-americano, por exemplo, se chama ARGUS-IS (Autonomous Real-Time Ground Ubiquitous Surveillance Imaging System), aludindo a Argos Panoptes, o gigante com cem olhos

4. Sobre o sonho militar, mas também capitalista, do ser humano que nunca dorme, ver 24/7: Capitalismo tardio e os fins do sono, de Jonathan Crary.

5. Uma questão importante a ser colocada, por exemplo, ao documentário “The Act of Killing", em que genocidas da Indonésia são convidados a dirigir o seu próprio filme e reencenar cenas de assassinato e tortura.

6. Para ler sobre a relação entre o livro de Bolaño, os poemas escritos no céu de Nova Iorque pelo poeta chileno Raul Zurita em 1982 intitulados "La vida nueva" e a 
ditadura chilena, ver a tese de Tiago Guilherme Pinheiro "Literatura sob rasura: autonomia, neutralização e democracia em J.M Coetzee e Roberto Bolaño".

7. "EU MESMO EXECUTEI, EM 1918 [durante a guerra, portanto], MUITOS VOOS EXPRESSIVOS E TESTES DE TEATRO AÉREO ELEMENTAR SOBRE O CAMPO DE BUSTO ARSIZIO. Eu constatei como é fácil para os espectadores seguirem todas as matizes do estado de ânimo do aviador, dada a identificação absoluta entre piloto e seu aparelho, que é como um prolongamento do corpo: os ossos, tendões, músculos e nervos se estendem à longarina e aos fios metálicos." [Tradução minha.]

8. Derrida, em "Force of Law", lê o texto de Benjamin, "Para uma crítica da violência", em uma chave perturbadora, talvez até injusta. Centralizando sua análise em torno da distinção feita por Benjamin entre a violência mítica (aquela que funda a lei) e a violência divina (aquela que destrói a lei, a aniquila em sua própria origem), Derrida faz uma pergunta sobre qual pensamento de Benjamin estaria já virtualmente formado ou articulado nesse ensaio sobre o tema da solução final.

9. Uma das armas seriamente cogitada (e testada inúmeras vezes) para a destruição do Japão após Pearl Harbor foi uma bomba incendiária desenvolvida pelo exército norte-americano que consistia em bombas amarradas a morcegos. A ideia era que os morcegos, soltos desde aviões, auxiliados na descida por paraquedas, alojariam-se nos forros de madeira das construções japonesas, e as bombas acopladas seriam detonadas por timers. Em um dos testes, os morcegos escaparam e explodiram uma base de testes do exército norte-americano. Um manual de artilharia do século XVI, escrito por Franz Helm, já sugeria explosivos amarrados a pombos e gatos.

10. Ou plus d'un, nos rastros de Derrida, sempre ao mesmo tempo mais que um, menos que um.

11. Segundo Alexandre Nodari, no texto "A literatura como antropologia especulativa", "o autor se objetiva, se obliqua em narrador, em personagens, em heterônimos, etc.; e, por sua vez, o leitor se subjetiva naqueles que, num texto literário, dizem eu. Além disso, está em jogo na ficção, como argumenta Milan Kundera, a exploração de um território novo da existência por meio de "egos imaginários", alter-egos: "o romance não examina a realidade, mas sim a existência. A existência não é o que aconteceu, a existência é o campo das possibilidades humanas, tudo aquilo que o homem pode tornar-se, tudo aquilo de que é capaz. Os romancistas desenham o mapa da existência descobrindo esta ou aquela possibilidade humana."

12. A psicografia coloca uma exigência dupla diante da noção de autoria, segundo pondera Alexandre Caroli Rocha em sua tese de mestrado sobre Parnaso do AlémTúmulo. Se, por um lado, reforça a ideia da autoria, que se estenderia para além do mundo dos viventes, por outro lado deflagra a sua instabilidade na figura do médium que a atualiza no mundo material.

\section{Referências:}

BARTHES, Roland. A Morte do Autor. In: O rumor da língua. São Paulo: Martins Fontes, 2004.

BAUER, Nancy. How to Do Things with Pornography. In: How to Do Things with Pornography. Cambridge: Harvard University Press, 2015.

BENJAMIN, Walter. Para a crítica da violência. In: Escritos sobre mitos e linguagem. São Paulo: Editora 34, 2013.

BENJAMIN, Walter. Sobre o conceito da história. In: Magia e técnica, arte e política. Ensaios sobre literatura e história da cultura. Obras escolhidas. V.1. São Paulo: Editora Brasiliense, 1987. 
BRETON, André. Manifesto do surrealismo. In: Manifestos do surrealismo. Rio de Janeiro, Nau, 2001.

BOLAÑO, Roberto. Estrella distante. Barcelona: Anagrama, 2001.

BUTLER, Judith. Notes Toward a Performative Theory of Assembly. Cambridge: Harvard University Press, 2015.

CHAMAYOU, Grégoire. Teoria do drone. São Paulo: Cosac Naify, 2015.

CRARY, Jonathan. 24/7 - Capitalismo tardio e os fins do sono. São Paulo: Cosac Naify, 2014.

DELILLO, Don. Point Omega. Nova Iorque: Charles Scribner’s Sons, 2010. (Paginação inexistente, leitura em Kindle)

DERRIDA, Jacques. Force of Law: 'The Mystical Foundation of Authority'. In: Acts of Religion. Nova Iorque, Routledge: 2002.

. Passions. In: On the Name. Stanford: Stanford University Press, 1995.

. Racism's Last Word. In: Critical Inquiry, 12:1 (Autumn, 1985).

'This Strange Institution Called Literature' An Interview with Jacques Derrida. In: Acts of Literature. Nova Iorque: Routledge, 1992.

FOUCAULT, Michel. O que é um autor? In: Estética, Literatura e Pintura, Música e Cinema. Rio: Forense Universitária, 2009.

HARAWAY, Donna. Situated Knowledges: The Science Question in Femininism and the Privilege of Partial Perspective. In: Simians, Cyborgs, and Women: The Reinvention of Nature. Nova Iorque: Routledge, 1991.

NODARI, Alexandre. A literatura como antropologia especulativa. In: Revista da Anpoll, n.38, Jan/Jun de 2015.

NOYS, Benjamin. Drone Metaphysics. In: Culture Machine, v.16, 2015.

PINHEIRO, Tiago Guilherme. A literatura sob rasura: autonomia, neutralização e democracia em J.M. Coetzee e Roberto Bolaño. Tese - Universidade de São Paulo. São Paulo, 2014.

ROCHA, Alexandre Caroli. A poesia transcendente de Parnaso do além-túmulo. Dissertação - Unicamp. Campinas, 2001.

TOMMASINI, Anthony. Music; The Devil Made Him Do It. The New York Times, Sept. 30, 2001. 